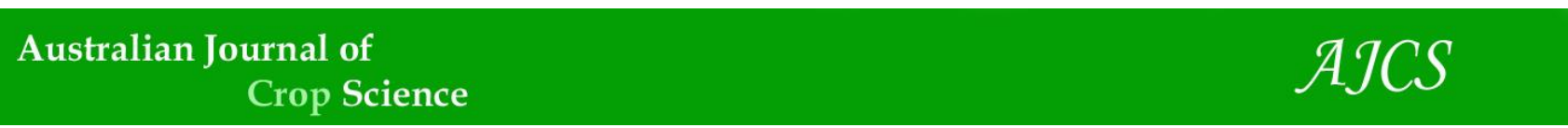

AJCS 14(08):1252-1258 (2020)

ISSN:1835-2707

doi: 10.21475/ajcs.20.14.08.p2339

\title{
Gas exchange and putrescine content as drought stress indicators in corn cultivars fertilized with silicon
}

\author{
Hudson Carvalho Bianchini ${ }^{1^{*}}$, Douglas Jose Marques ${ }^{2}$ \\ ${ }^{1}$ José do Rosário Vellano University-UNIFENAS, Alfenas, MG 37130-000, Brazil \\ ${ }^{2}$ Institute of Agricultural Sciences, Federal University of Uberlândia, Monte Carmelo, Brazil
}

"Corresponding author: hudson.bianchini@unifenas.br

Abstract

The effects of drought stress on maize have been extensively reported in tropical and subtropical areas, including morphological changes in plants and reductions in the grain yield. The development of sustainable alternatives that help mitigate the negative impacts of water stress is indispensable for the development of agricultural crops. This study evaluates the effect of silicon fertilization in two irrigation blades, on gas exchange, putrescine content, quantification of $\mathrm{Ca}, \mathrm{K}, \mathrm{Zn}$, and Fe by neutron activation and grain yield in two maize cultivars, tolerant and sensitive to drought stress. Two experiments were conducted, the first using BR1010 (sensitive to drought stress) and the second using DKB-390 (tolerant to drought stress), in $19 \mathrm{dm}^{-3}$ pots with one plant in each pot. The experiment was organized in randomized blocks, in a factorial scheme, combining two irrigation blades ( 30 percent and 100 percent of necessary water replacement) and two silicon conditions per pots: control (-Si), and $27 \mathrm{~g} \mathrm{Si} \mathrm{(+Si)} \mathrm{using} \mathrm{calcium} \mathrm{silicate}$ (10.5 percent $\mathrm{Si}$ ) with four replicates. The contents of putrescine, $\mathrm{Ca}, \mathrm{K}, \mathrm{Zn}$, and $\mathrm{Fe}$, as well as transpiration rate, stomatal conductance, and net photosynthetic contents were quantified. Maize yield was measured at the end of the study. It was concluded that supplementation with Si contributes to a 12 percent increase in yield for BR-1010 (drought sensitive) and 14 percent for DKB-390 (drought tolerant). Si increased the net photosynthetic rate, transpiration rate, and stomatal conductance in DKB-390. The content of putrescine increased in plants submitted to drought stress and can be considered as an indicator of drought stress. The leaf contents of $\mathrm{Ca}, \mathrm{K}, \mathrm{Zn}$, and Fe varied according to the cultivars and water blade studied.

Keywords: Calcium Silicate, Neutron activation analysis, Polyamines, Stress Tolerance, Water use efficiency, Zea mays L.

Abbreviations: $\mathrm{Ca}$, calcium; Fe, iron; K, potassium; PAs, polyamines; Put, putrescine; ROS, reactive oxygen species; $\mathrm{Si}$, silicon; $\mathrm{Zn}$, zinc.

\section{Introduction}

Drought stress caused by water scarcity is one of the critical factors that limits maize yields in most maize production regions worldwide (Cooper et al., 2014). In tropical and subtropical regions, the irregular distribution of rainfall favours water stress, which affects several physiological and biochemical processes, reducing the development of cultivated plants. Fertilization with silicon (Si) may be a viable alternative to attenuate the harmful consequences of water stress in plants of the Poaceae family, such as corn (Rao, 2017). The application of $\mathrm{Si}$ in soils with limited moisture increases the growth and yield of corn hybrids due to the improvement in the photosynthetic rate, higher osmotic adjustment, and increase in water content and decrease in transpiration (Amin et al., 2018). The main mechanism for the relief of abiotic stress by $\mathrm{Si}$ is its deposition on the cuticles, which prevents water loss through evapotranspiration and protects plants facing a water deficit (Ma et al., 2015). Under drought stress conditions, Si-mediated mechanisms that are involved in water consumption by the plant root include increasing the osmotic motive force via active adjustment, the improvement in the transport activity of aquaporins at the transcriptional and post-transcriptional levels, the modification in root growth, and the increase in the root/shoot ratio (Chen et al., 2016).

To understand the physiological parameters in plant response to drought stress, it is necessary to evaluate a set of metabolites, especially polyamines (PAs), which are aliphatic organic bases belonging to low molecular weight bioactive amines, essential for cell growth and functions and interacting with many macromolecules. As a consequence of these various interactions, PAs trigger a series of cellular effects, acting as inactivating enzymes of reactive oxygen species (ROS), coenzymes, and as regulatory molecules (Leite et al., 2012). They are an effective cross-protection mechanism against biotic threats, providing a link between abiotic and biotic stress responses (Arbona et al., 2013). Among the PAs found in plants, the most abundant are putrescine, spermidine, and spermine.

Studies show that Si may change plant tolerance to drought stress. Plants grown with $\mathrm{Si}$ have altered responses in nutrient uptake and reduced toxic accumulation of iron and manganese and other heavy metals such as aluminium and increased phosphorus uptake (Zhu et al., 2004). Si application increased the uptake of transcellularly transported elements like $\mathrm{K}, \mathrm{P}, \mathrm{Zn}$, and Fe. In contrast, Ca 
uptake, which occurred via both apoplastic and transcellular pathways, was decreased by Si application, possibly through the reduction of apoplastic uptake (Mehrabanjoubani et al., 2015).

The nutrients that have been taken up by plants under stress can be quantified by several methods. Among them, the multi-elemental technique, neutron activation analysis, $k_{0}$ method (INAA- $k_{0}$ ), has been successfully applied in the determination of the elemental concentration of soils, plants, and fertilizers (Menezes and Jacimovic, 2011). The principle of this technique is to irradiate a sample by neutron flux in a nuclear reactor to produce radionuclides and measure gamma emissions, determining several chemical elements.

Therefore, this study tests the following hypothesis: an increase in $\mathrm{Si}$ absorption may favour basic aspects physiological and nutritional aspects and putrescine levels, resulting in increased grain yield in maize grown under water deficit. Thus, this study investigates the effect of silicon fertilization in two irrigation blades, on gas exchange, putrescine content, quantification of $\mathrm{Ca}, \mathrm{K}, \mathrm{Zn}$, and $\mathrm{Fe}$ by neutron activation and grain yield in two maize cultivars, tolerant and sensitive to drought stress.

\section{Results and Discussion}

\section{Gas exchange}

The addition of $\mathrm{Si}$ increased the net photosynthetic rate of BR-1010 (sensitive) with 30 percent irrigation blade (Fig. 2A). DKB-390 (tolerant) $+\mathrm{Si}$ increased the net photosynthetic rate in the 100 percent irrigation blade (Fig. 2B). This result demonstrates that Si-treated plants exhibit higher photosynthesis once they have more stable chloroplasts due to better hydration and greater stomatal conductance (Figs. $2 \mathrm{D}$ and $2 \mathrm{~F}$ ). Drought stress directly affects photosynthesis rates, limiting $\mathrm{CO}_{2}$ diffusion to the substomatic chamber. The oxidative stress resulting from abiotic and biotic stress affects photosynthesis, impacting the main enzymes of the Calvin cycle and the photosynthetic electron transport chain (Gong and Chen, 2012). In the leaves, Si fills the interfibrillar spaces and reduces the movement of water through the cell wall, which conserves the water and can reduce the transpiration rate (Marafon and Endres, 2013).

Maize cultivars studied presented a different behaviour in relation to transpiration rate (Figs. $2 \mathrm{C}$ and $2 \mathrm{D}$ ). The highest values were observed in BR-1010 (sensitive) +Si under drought stress conditions (30 percent irrigation). Alternatively, for DKB-390 (tolerant), the highest values were observed $+\mathrm{Si}$ no drought stress. Therefore, $+\mathrm{Si}$ increased the transpiration rates, which favoured the net photosynthesis rate (Figs. $2 \mathrm{~A}$ and $2 \mathrm{~B}$ ). Si supplementation may not affect maize cuticular transpiration of the leaf, but it significantly reduces stomatal transpiration (Gao et al., 2006). In this case, not only may an increase in drought tolerance be associated with leaf transpiration, but also root water absorption since the reduction in water loss by transpiration is not the only mechanism mediated by $\mathrm{Si}$ in plants (Shi et al., 2016). After the addition of Si, transpiration increases (Chen et al., 2011) in some plants, while in others it is reduced (Gao et al., 2006), or no change is observed (Hattori et al., 2008), indicating different strategies among species to balance water absorption and loss on the leaf surface.
$+\mathrm{Si}$ increases stomatal conductivity in two cultivars studied (Figs. 2E and 2F), indicating that $\mathrm{Si}$ influences the stomatal movement of plants. To prevent the leaf water potential from falling below critical levels for the stability of the water transport system, stomatal conductance is decreased (Oren et al., 1999). Silicon supplementation may increase the photosynthetic rate, being associated with positive effects on stomatal conductance and transpiration under stress conditions (Yao et al., 2011). Si does not always decrease plant transpiration. Hattori et al. (2005) observed an increase in stomatal conductance and transpiration rate of leaves in potted sorghum by supply of Si under drought stress. Similar results were also observed in droughtstressed wheat (Gong et al., 2008) and rice (Chen et al., 2011).

\section{Put content}

Put concentration was higher under drought stress in both cultivars (Figs. $3 \mathrm{~A}$ and $3 \mathrm{~B}$ ). + $\mathrm{Si}$ increased Put level in BRS1010 (sensitive) and decreased in DKB-390 (tolerant). However, when there is no drought stress (100 percent irrigation), the levels of Put in the two cultivars had the lowest values on $+\mathrm{Si}$, which shows that the increase in Put level relates to drought resistance, regulating stress signaling. Plants under stress conditions accumulate several osmolytes, such as PAs, especially Put, which is one of the most abundant (Leite et al., 2012). PAs have metabolic pathways interconnected with different routes in the formation of molecules and metabolites that signal plant responses to stress (Farriduddin et al., 2013). The PAmediated regulation in response to water stress suggests that they are potentially useful in overcoming the damaging effects of drought, stabilizing the cytoplasmic membrane, as well as acting as a free radical scavenger (Monteiro et al., 2014). Many studies show that foliar application of Put at an appropriate level can trigger physiological processes and induce the biosynthesis of osmotic adjustment substances, such as free amino acids, soluble sugars, and proline. This may compensate for the negative impacts of drought stress on plant biomass and increase the quality and quantity of certain bioactive substances (Sánchezrodríguez et al., 2016; Mohammadi et al., 2018).

\section{Nutrient absorption rate}

Significant differences in nutrient contents were found between cultivars and as a function of irrigation blades, being that different metabolic activities can explain the absorption rate of the cultivars in function of the studied variables. In BR-1010 (sensitive), +Si increased 50 percent and 110 percent, respectively, the contents of $\mathrm{Ca}$ and $\mathrm{Zn}$ (Figs. 4A and $4 \mathrm{E}$ ) in drought stress (30 percent irrigation). Reduction in contents of $\mathrm{Ca}$ and increased $\mathrm{Zn}$ in the leaves of DKB-390 when + Si was used (Figs 4B and 4F). Si application prevented certain symptoms of $\mathrm{Zn}$ and $\mathrm{Mn}$ deficiency (necrotic spots), most likely due to its indirect effect by enhancing antioxidant defense capacity in plant tissues (Bityutskii et al., 2014). Uptake and transport of $\mathrm{Zn}$ in maize are significantly decreased by the incorporation of Si (Kaya et al., 2009). Alternatively, in rice with the addition of Si considerably increased root $\mathrm{Zn}$ concentrations in both cultivars to different degrees (Song et al., 2011). The increase in Ca uptake observed in BR-1010 at the drought stress (30 percent irrigation) may be ascribed to a diminution in plasma membrane penetrability and an increase in the movement of plasma membrane $\mathrm{H}+$-ATPase 


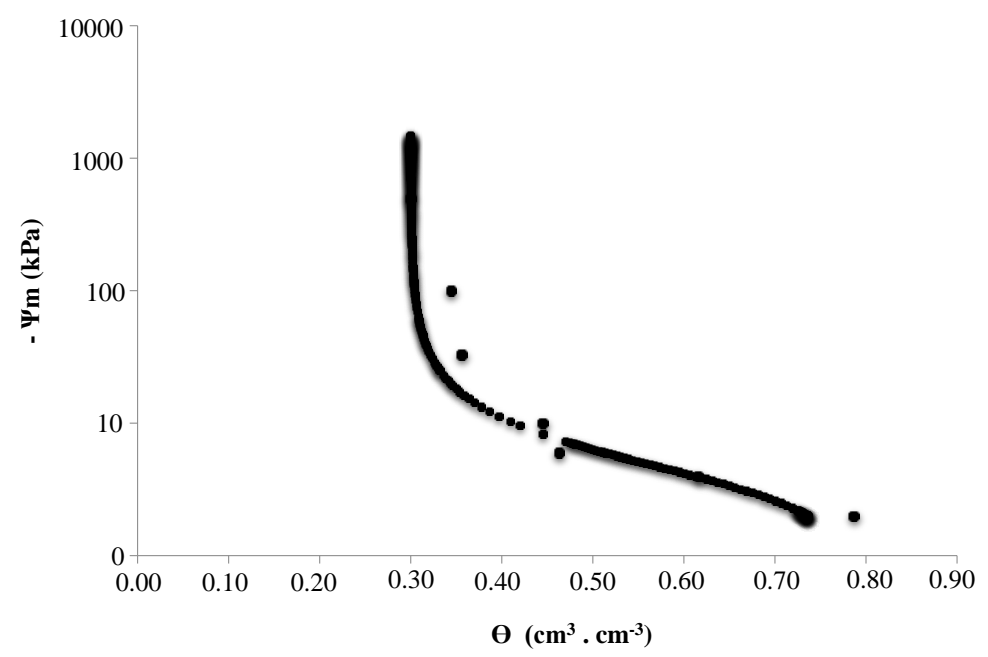

Fig 1. Water retention characteristic curve of the Oxisol used in the research. The moisture value in the field capacity found was the matrix potential of $0.4695 \mathrm{~cm} 3 \mathrm{~cm}-3$ for a voltage of $7.36 \mathrm{kPa}$.
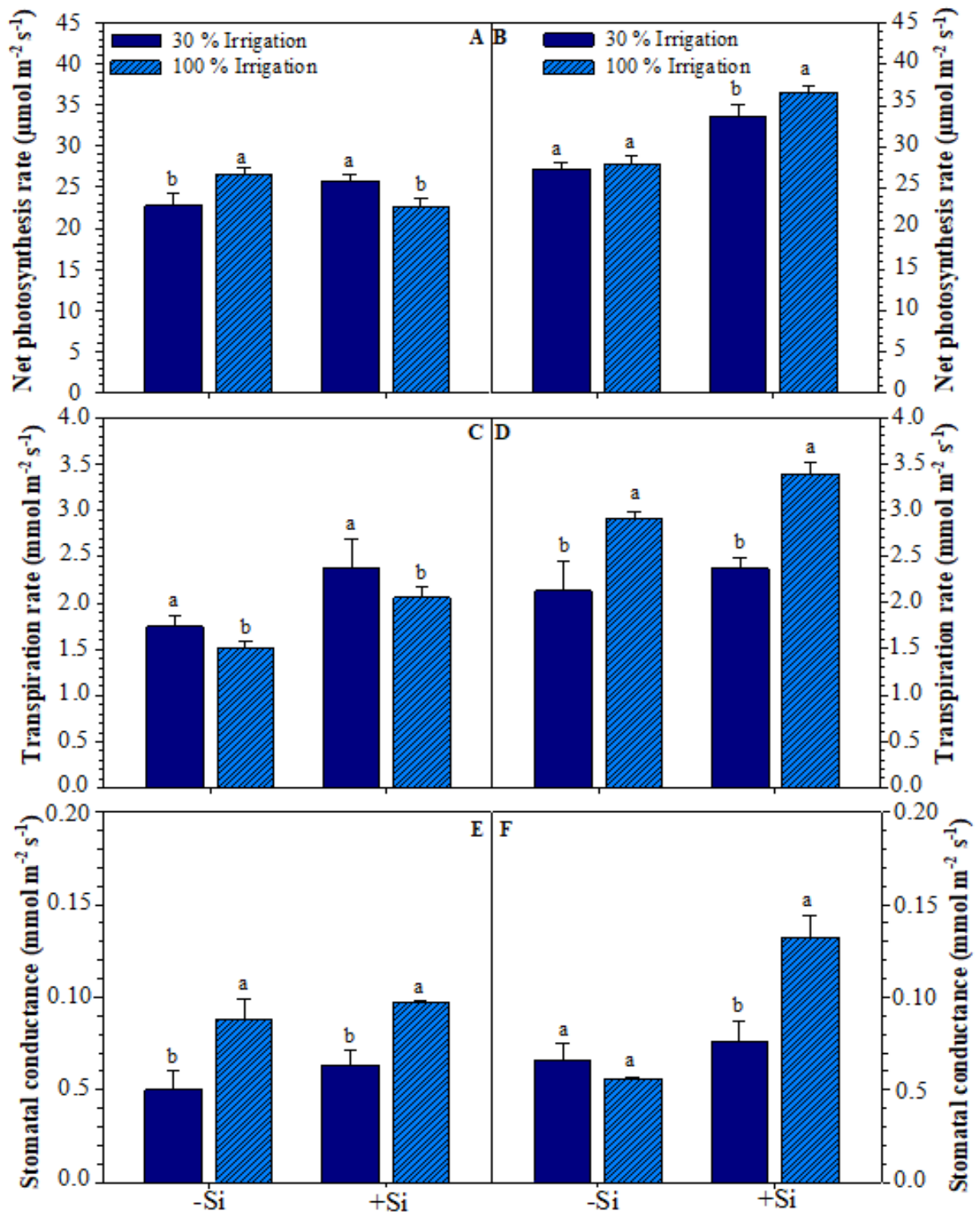

Fig 2. Net photosynthetic rate, transpiration rate and stomatal conductance in $B R-1010$ ( $A, C, E)$ and DKB-390 (B, D, F) in maize exposed to $-\mathrm{Si}$ and $+\mathrm{Si}$ and two irrigation blades ( 30 and $100 \%$ of necessary water reposition). Means followed by the same letter are not significantly different by the Tukey test at $5 \%$ of probability. The bars represent the mean standard error. 


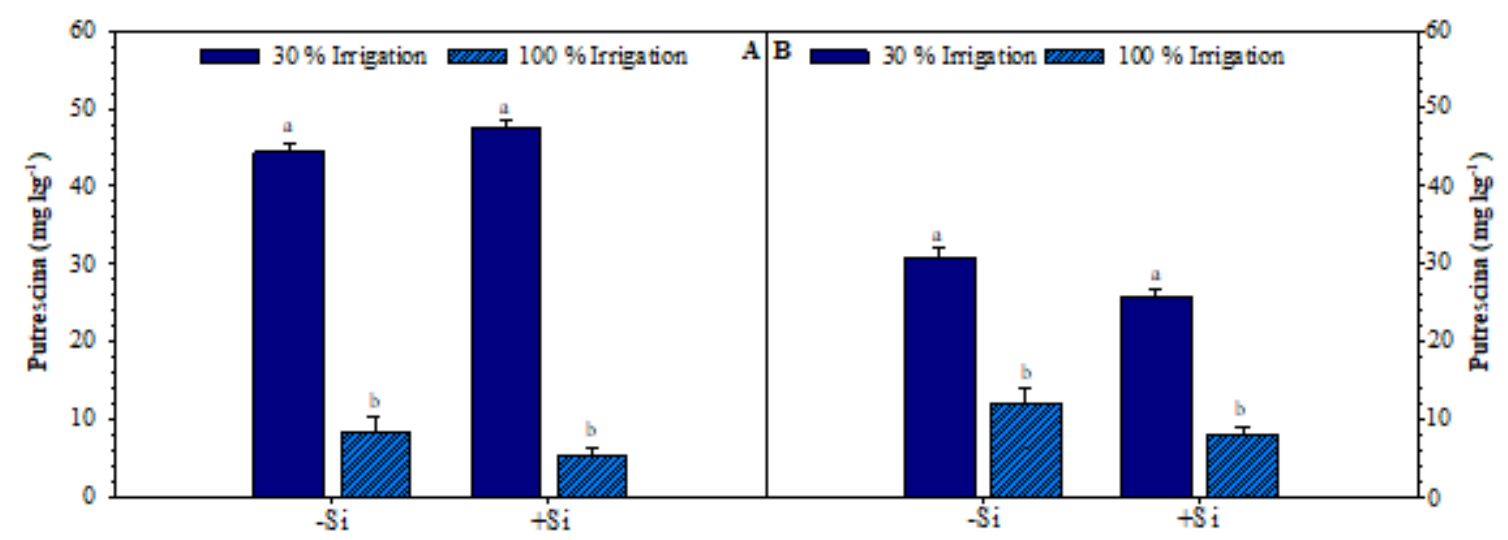

Fig 3. Concentration of putrescine in maize leafs BR-1010 (A) and DKB-390 (B) exposed to $-\mathrm{Si}$ and $+\mathrm{Si}$ and two irrigation blades (30 and $100 \%$ of water necessity reposition). Means followed by the same letter are not significantly different by the Tukey test at $5 \%$ of probability. The bars represent the mean standard error.

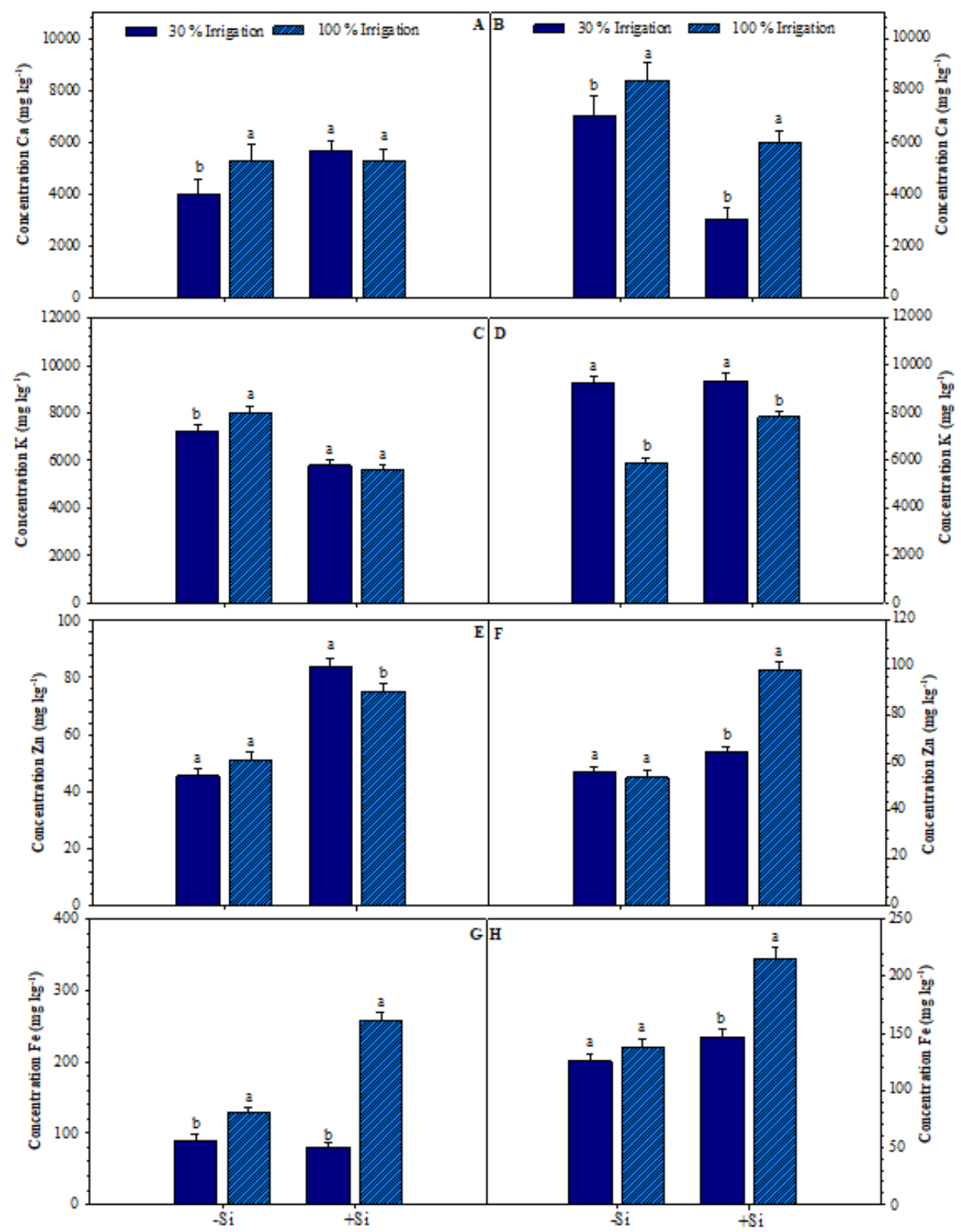

Fig 4. Concentration of $\mathrm{Ca}, \mathrm{K}, \mathrm{Zn}$ and $\mathrm{Fe}$ in maize leafs BR-1010 ( $\mathrm{A}, \mathrm{C}, \mathrm{E}$ and $\mathrm{G})$ and DKB-390 (B, D, F and $\mathrm{H}$ ) exposed to -Si and $+\mathrm{Si}$ and two irrigation blades (30 and $100 \%$ of water necessity reposition). Means followed by the same letter are not significantly different by the Tukey test at $5 \%$ of probability. The bars represent the mean standard error. 


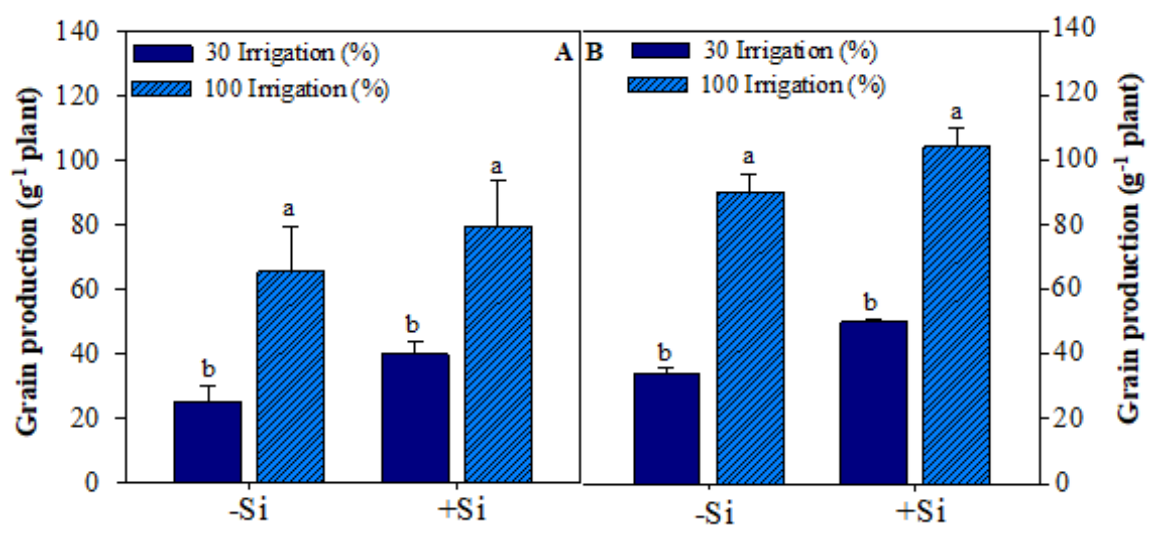

Fig 5. Grain yield BR-1010 (A) and DKB-390 (B) in maize exposed to $-\mathrm{Si}$ and +Si and two irrigation depths ( 30 and $100 \%$ of water necessity reposition). Means followed by the same letter are not significantly different by the Tukey test at $5 \%$ of probability. The bars represent the mean standard error.

due to the addition of Si (Kaya et al., 2006). Plants with different $\mathrm{Si}$ accumulation capacities may respond differentially. If the apoplastic pathway is prevented by $\mathrm{Si}$ deposition, the uptake of some elements such as $\mathrm{Ca}^{2+}$ may be decreased (Brackhage et al., 2013; Mehrabanjoubani et al., 2015).

Alternatively, $\mathrm{K}$ had a different behaviour between the two cultivars studied (Figs. 4C and 4D), being absorbed in greater quantity when $+\mathrm{Si}$ and $-\mathrm{Si}$, under conditions of drought stress (30 percent irrigation) in DKB-390 (tolerant), indicating that the application of $\mathrm{Si}$ can affect soil $\mathrm{K}$ availability and nutrient content in plants (Chen et al., 2016). There was no significant difference between the levels of $\mathrm{K}$ in cultivar BRS1010 (sensitive) when + Si and -Si.

Fe was absorbed in greater quantity with $+\mathrm{Si}$, mainly in DKB390 (Fig. 4H), which could be a result of the increase the apoplastic Fe pool, together with the enhanced expression of genes involved in biosynthesis of Fe-mobilizing compounds in roots. Si can also increase the absorption of $\mathrm{Fe}$ as a function of its distribution in the plant and increase Fe transport from root to shoot (Fu et al., 2012, You-Qiang et al., 2012). Plants fertilized with Si display both greater short- and long-term Fe uptake (Mali and Aery, 2009).

\section{Grain yield}

+Si contributes to a 12 percent increase in yield for BR-1010 (sensitive) and 14 percent for DKB-390 (tolerant) (Figs. 5A and $5 B$ ). The drought stress reduced grain yield, but supplementation with Si favoured an increase in corn yield, reducing negative effects. The deleterious effects of drought are minimized by Si nutrition due to several physiological changes, such as the increase in photosynthetic rate (Kurdali et al., 2013), maintenance of photosynthetic mechanisms (Chutipaijit et al., 2012) and higher water retention in plants (Ahmed et al., 2013).

Supplementation with $\mathrm{Si}$ contributes to a 12 percent increase in yield for BR-1010 (drought stress sensitive) and 14 percent for DKB-390 (drought stress tolerant). Si increased the net photosynthetic rate, transpiration rate, and stomatal conductance in DKB-390. Increased putrescine content in plants can be considered an indicator of drought stress. The leaf contents of $\mathrm{Ca}, \mathrm{K}, \mathrm{Zn}$, and Fe varied according to the cultivars and water blade studied.

\section{Materials and Methods}

\section{Study site and plant material}

The experiment was conducted during 2018 under greenhouse conditions. Two contrasting maize cultivars were used, distinct in terms of drought tolerance - more specifically, DKB-390 (tolerant) and BRS-1010 (sensitive). When compared with BRS-1010 (sensitive), the DKB-390 (tolerant) has an increase in exoderm thickening, a greater number of metaxylem elements, a smaller diameter of the vessel elements and in leave, a greater number of stomata occurs as well as a smaller distance between the vascular bundles. The seeds were obtained from EMBRAPA Maize and Sorghum, Brazil.

\section{Chemical and physical soil analysis}

The soil was classified as Oxisol (Embrapa, 2013). Samples were collected at a blade of 0 to 20 centimetres. The samples were placed to dry, crushed through a five millimetre sieve and mixed to describe the chemical and physical compositions. After application of limestone and calcium silicate, the soil remained under incubation for 45 days. Fertilization was performed for macronutrients and micronutrients and, following the recommendation of Marques et al. (2014), adapted for experiments conducted in pots for maize crops.

\section{Experimental design}

Two experiments were conducted, with the first using BR1010 (sensitive to drought stress) and the second using DKB390 (tolerant to drought stress), planted in $19 \mathrm{dm}^{-3}$ pots with one plant in each pot. Each experiment was organized in randomized blocks, in a factorial scheme, combining two irrigation blades ( 30 percent and 100 percent of necessary water replacement) and two silicon conditions per pots: control $(-\mathrm{Si})$ and $27 \mathrm{~g} \mathrm{Si}(+\mathrm{Si})$, using calcium silicate (10.5 percent $\mathrm{Si}, 25$ percent $\mathrm{Ca}$ ), in four replicates.

\section{Equipment and irrigation management}

Parameters of the soil water retention curve used in the irrigation blade quantification and irrigation management 
(Fig. 1) were obtained based on the model proposed by Genuchten (1980). The moisture value in field capacity was $0.3458 \mathrm{~m}^{3}$ for voltage $-30 \mathrm{kPa}$. Irrigation management was carried out based on the water retention curve in the soil and in Watermark readings (Soil Moisture Meter) installed at a blade of 0.15 metres. Irrigation was performed whenever soil water stress reached $-30 \mathrm{kPa}$ in each treatment as recommended by Guerra (1994). Readings were taken daily at 5 p.m. Additionally, devices were installed to quantify the matrix potential at the greatest tensions at 30 percent and 100 percent of the ideal blade.

Irrigation was based on the water retention curve linked to soil and tensiometer measurements, installed at a blade of 0.15 metres. Irrigation was implemented when water tension in soil reached $-30 \mathrm{kPa}$ and at irrigation blade (30 percent and 100 percent of necessary rate for water recovery in the soil). All measurements were carried out daily at 5 p.m. and soil moisture metres (Watermark, 200Ss5 ) were installed to quantify the matrix potential only at two higher tensions ( 30 percent and 100 percent of the ideal soil blade).

\section{Neutron activation analysis, standardized $k_{0}$ method}

The elemental concentration determinations of $\mathrm{Ca}, \mathrm{K}, \mathrm{Zn}$, and $\mathrm{Fe}$ in plant leaves tissues were carried out by neutron activation analysis, $k_{0}$-method (Menezes et al., 2014) at the Nuclear Technology Development Centre, located in Belo Horizonte, MG. Irradiations were carried out in the TRIGA MARK I IPR-R1 nuclear research reactor. Other essential elements were not quantified since they did not have suitable nuclear characteristics to be analyzed by this technique.

\section{Physiological aspects}

Transpiration rate, stomatal conductance, and net photosynthetic rate was measured by Infrared Gas Analyzer (IRGA, model LI-6400) in the adaxial surface of fully expanded leaves. Photosynthetic water use efficiency was estimated according to Fischer and Maurer (1978). Gas exchange was evaluated between 9 a.m. and 12 a.m. in all plants. Irradiance was kept at $1,000 \mu \mathrm{mol} \mathrm{m} \mathrm{m}^{-1}$ during the measurements.

\section{Determination of putrescine}

The Put was determined according to Gloria et al. (2005). The identification of the putrescine was performed by comparison to those of standard solution. Quantification was accomplished by direct interpolation in the standard curves ( $R 2 \geq 0.9926)$. The determination limits for putrescine was $0.02 \mathrm{mg} / 100 \mathrm{gm}$.

\section{Agronomic measurements}

At the end of the study, grain maize yield in each treatment was measured at harvest in $\mathrm{g} \mathrm{plant}^{-1}$.

\section{Statistical analysis}

Data were subjected to variance analysis (ANOVA) and when significant differences occurred; Tukey test at $5 \%$ level of error probability $(p \leq 0.05)$ was applied. All statistical procedures were carried out with the SISVAR ${ }^{\circ}$ software (Ferreira, 2014).

\section{Acknowledgments}

Authors are thankful to the Conselho Nacional de Desenvolvimento Científico e Tecnológico (CNPq) and Fundação de Amparo à Pesquisa do Estado de Minas Gerais (FAPEMIG) for supporting this study.

References

Ahmed M, Kamran A, Asif M, Qadeer U, Ahmed ZI, Goyal A (2013) Silicon priming: a potential source to impart abiotic stress tolerance in wheat: A review. Aust J Crop Sci. 7: 484-491.

Amin M, Ahmad R, Ali A, Hussain I, Mahmood R, Aslam M, Lee DJ (2018) Influence of Silicon Fertilization on Maize Performance Under Limited Water Supply. Silicon. 10: 177 183.

Arbona V, Manzi M, Ollas CD, Gómez-Cadenas A (2013) Metabolomics as a tool to investigate abiotic stress tolerance in plants. Int J Mol Med Sci. 14: 4885-4911.

Bityutskii N, Pavlovic J, Yakkonen K, Maksimovic V, Nikolic M (2014) Contrasting effect of silicon on iron, zinc and manganese status and accumulation of metal-mobilizing compounds in micronutrient-deficient cucumber. Plant Physiol Biochem. 74: 205-211.

Brackhage C, Schaller J, Bäucker E, Dudel, EG (2013) Silicon availability affects the stoichiometry and content of calcium and micro nutrients in the leaves of common reed. Silicon. 5: 199-204.

Chen W, Yao X, Cai K, Chen J (2011) Silicon alleviates drought stress of rice plants by improving plant water status, photosynthesis and mineral nutrient absorption. Biol Trace Elem Res. 142: 67-76.

Chen D, Cao B, Wang S, Liu P, Deng X, Yin L, Zhang S (2016) Silicon moderated the $\mathrm{K}$ deficiency by improving the plantwater status in sorghum. Sci Rep. 6, 22882.

Chutipaijit S, Chaum S, Sompornpailin K (2012) An evaluation of water deficit tolerance screening in pigmented indica rice genotypes. Pak J Bot. 44: 65-72.

Cooper M, Gho C, Leafgren R, Tang T, Messina C (2014) Breeding drought-tolerant maize hybrids for the US cornbelt: Discovery to product. J Exp Bot. 65: 6191-6204.

Embrapa-Empresa Brasileira de Pesquisa Agropecuária (2013) Brazilian System of Soil Classification, 3a edn. Embrapa Soils, Brasília.

Fariduddin Q, Varshney P, Yusuf M, Ahmad A (2013) Polyamines: potent modulators of plant responses to stress. J Plant Interact. 8: 1-16.

Ferreira DF (2014) Sisvar: a guide to your bootstrap multiple comparison procedures. Cienc Agrotec. 38: 109-112.

Fischer RA, Maurer R (1978) Drought resistance in spring wheat cultivars: Grain yield responses in spring wheat. Aust J Agric Res. 29: 892-912.

Fu YQ, Shen H, Wu DM, Cai KZ (2012) Silicon mediated amelioration of $\mathrm{Fe}^{2+}$ toxicity in rice (Oriza sativa $\mathrm{L}$.) roots. Pedosphere. 22: 795-802.

Gao X, Zou C, Wang L, Zhang F (2006) Silicon Decreases Transpiration Rate and Conductance from Stomata of Maize Plants. J Plant Nutr. 29: 1637-1647. 
Genuchten MV (1980) A closed-form equation for predicting the hydraulic conductivity of unsaturated soils. Soil Sci Soc Am J. 44: 892-898.

Glória MBA, Tavares-Neto J, Labanca RA, Carvalho MS (2005) Influence of cultivar and germination on bioactive amines in soybeans (Glycine max L. Merril). J Agric Food Chem. 53: 7480-7485.

Guerra AF (1994) Irrigation management under cerrado conditions aiming at the production potential. Pesqui Agropecu Bras. 29: 1111-1118.

Gong HJ, Chen KM, Zhao ZG, Chen GC, Zhou WJ (2008) Effects of silicon on defense of wheat against oxidative stress under drought at different developmental stages. Biol Plantarum. 52: 592-596.

Gong H, Chen K (2012) The regulatory role of silicon on water relations, photosynthetic gas exchange, and carboxylation activities of wheat leaves in field drought conditions. Acta Physiol Plant. 34: 1589-1594.

Hattori T, Inanaga S, Araki H, An P, Morita S, Luxová M, Lux A (2005) Application of silicon enhanced drought tolerance in Sorghum bicolour. Physiol Plant. 123: 459-66.

Hattori T, Sonobe K, Inanaga S, Na P, Morita S (2008) Effects of Silicon on Photosynthesis of Young Cucumber Seedlings Under Osmotic Stress. J Plant Nutr. 31: 1046-1058.

Kaya C, Tuna L, Higgs D (2006) Effect of silicon on plant growth and mineral nutrition of maize grown under waterstress conditions. J Plant Nutr. 29: 1469-1480.

Kaya C, Tuna AL, Sonmez O, Ince F, Higgs D (2009) Mitigation effects of silicon on maize plants grown at high zinc. J Plant Nutr. 32: 1788-1798.

Kurdali F, Al-Chammaa M, Mouasess A (2013) Growth and nitrogen fixation in silicon and/or potassium fed chickpeas grown under drought and well-watered conditions. J Stress Physiol Biochem. 9: 385-406.

Leite GA, Carvalho CAC, Freitas WES, Dantas JIA, Pontes CA, Fernandes PLO (2012) A ação das poliaminas na maturação e senescência de frutos. ACSA. 8: 08-21.

Ma J, Cai H, He C, Zhang W, Wang L (2015) A hemicellulosebound form of silicon inhibits cadmium ion uptake in rice (Oryza sativa) cells. New Phytol. 206: 1063-1074.

Mali M, Aery NC (2009) Effect of silicon on growth biochemical constituents, and mineral nutrition of cowpea. Commun Soil Sci Plant Anal. 40: 1041-1052.

Marafon AC, Endres L (2013) Silicon: fertilization and nutrition in higher plants. Rev Cienc Agrar. 56: 380-388.

Marques DJ, Broetto F, Ferreira MM, Lobato AKS, Ávila FW, Pereira FJ (2014) Effect of potassium sources on the antioxidant activity of eggplant. Rev Bras Cienc Solo. 31: 1836-1842.
Mehrabanjoubani PA, Abdolzadeh A, Sadeghipour HR, Aghdasi M (2015) Silicon affects transcellular and apoplastic uptake of some nutrients in plants. Pedosphere. 25: 192-201.

Menezes MABC, Jaćimović $R$ (2011) $k_{0}$-INAA quality assessment by analysis of soil reference material GBW07401 using the comparator and neutron flux monitor approaches. Appl Radiat Isot. 69: 1057-1063.

Menezes MABC, Jacimovic R (2014) Implementation of a methodology to analyze cylindrical 5-g sample by neutron activation technique, k0 method, at CDTN/CNEN, Belo Horizonte. J Radioanal Nucl Chem. 300: 523-531.

Mohammadi H, Ghorbanpour M, Brestic M (2018) Exogenous putrescine changes redox regulations and essential oil constituents in field-grown Thymus vulgaris $\mathrm{L}$. under well-watered and drought stress conditions. Ind Crops Prod. 122: 119-132.

Monteiro JG, Cruz JR, Nardin MB, Santos DMMS (2014) Crescimento e conteúdo de prolina em plântulas de guandu submetidas a estresse osmótico e à putrescina exógena. Pesqui Agropecu Bras. 49: 18-25.

Oren R, Sperry JS, Katul GG, Pataki DE, Ewers BE, Phillips, Schäfer KVR (1999) Survey and synthesis of intra- and interspecific variation in stomatal sensitivity to vapor pressure deficit. Plant Cell Environ. 22: 1515-1526.

Rao GB, Yadav PIP, Syriac EK (2017) Silicon nutrition in rice-A review. J Pharmacogn Phytochem. 6: 390-392.

Sánchezrodríguez E, Romero L, Ruiz JM (2016) Accumulation of free polyamines enhances the antioxidant response in fruits of grafted tomato plants under water stress. J Plant Physiol. 190: 72-78.

Shi Y, Zhang Y, Han W, Feng R, Hu Y, Guo J, Gong H (2016) Silicon enhances water stress tolerance by improving root hydraulic conductance in Solanum lycopersicum L. Front Plant Sci. 7: 196

Song AL, Li P, Li ZJ, Fan FL, Nikolic M, Liang YC (2011) The alleviation of zinc toxicity by silicon is related to zinc transport and antioxidative reactions in rice. Plant Soil. 344: 319-333.

Yao X, Chu J, Cai K, Liu L, Shi J, Geng W (2011) Silicon improves the tolerance of wheat seedlings to Ultraviolet-B stress. Biol Trace Elem Res. 143: 507-517.

You-Qiang, FU, Hong S, Dao-Ming WU, Kun-Zheng CAI (2012) Silicon-mediated amelioration of $\mathrm{Fe}^{2+}$ toxicity in rice (Oryza sativa L.) roots. Pedosphere. 22: 795-802.

Zhu Z, Wei G, Li J, Qian Q, Yuet J (2004) Silicon alleviates salt stress and increases antioxidant enzymes activity in leaves of salt-stressed cucumber (Cucumis sativus L.). Plant Sci. 167: 527-533. 